\title{
Analisis Sistem Jaringan Komputer Di Sekolah Menengah Kejuruan Al-Madani Pontianak
}

\author{
Isnania Lestari $1^{*}$, Ryan Permana ${ }^{2}$ \\ 1,2Program Studi Pendidikan Teknologi Informasi dan Komputer IKIP PGRI Pontianak
}

\section{A R T I C L E I N F O}

Article history:

Received 19 February 2018

Received in revised form 10 March 2018

Accepted 12 April 2018

Available online 25 May

2018

Kata Kunci:

SMK, Jaringan, Komputer

Keywords:

Vocational School

Networking,Computer

\begin{abstract}
A B S T R A K
Pentingnya membangun sebuah jaringan komputer antara lain supaya lebih mudah, cepat dan efisien dalam sharing data, berkomunikasi antar pengguna dalam sebuah jaringan, dan juga kemanan data dapat terjaga dengan baik. Di SMK Al-Madani Pontianak telah terdapat laboratorium komputer, namun belum memiliki jaringan komputer yang terintegrasi, baik jaringan dalam laboratorium komputer tersebut maupun ruangan kepala sekolah, ruangan guru, dan ruangan tata usaha. Penelitian ini merupakan penelitian kualitatif deskriptif dengan teknik analisis deskriptif. Dengan teknik pengumpulan dan penyusunan data menggunakan teknik triangulasi. Berdasarkan hasil penelitian, SMK Al-Madani membutuhkan sebuah sistem jaringan komputer yang terintegrasi. Untuk sistem jaringan di dalam laboratorium komputer dibutuhkan 30 unit komputer siswa dan 1 unit komputer guru, dan dihubungkan dengan kabel. Sedangkan untuk jaringan ruangan kepala sekolah, ruangan guru, dan ruangan tata usaha dibutuhkan jaringan wireless. Komponen wireless digunakan kepala sekolah, guru, dan staff untuk mengakses jaringan komputer melalui laptop pribadi. IP Address yang digunakan dalam system jaringan ini adalah menggunakan IP dynamic.
\end{abstract}

A B S T R A C T

The importance of build a computer network includes making it easier, faster and more efficient in sharing data, communicating between users on a network, and also maintaining data security. At SMK Al-Madani Pontianak there is a computer laboratory, but it does not yet have an integrated computer network, both the network in the computer laboratory and the principal's room, the teacher's room, and the administration room. This research is a descriptive qualitative study with descriptive analysis techniques. With data collection and compilation techniques using triangulation techniques. Based on the results of the study, Al-Madani Vocational School needed an integrated computer network system. For a network system in a computer laboratory, 30 units of student computers and 1 unit of a teacher's computer are needed, and connected by cable. As for the principal's room network, the teacher's room, and the administrative room needed wireless networks. Wireless components are used by principals, teachers, and staff to access computer networks through personal laptops. The IP address used in this network system is using IP dynamic.

\footnotetext{
* Corresponding author.

E-mail addresses: isnanialestari@gmail.com (Isnania Lestari), ryanpermana.hidayat@gmail.com (Ryan Permana)
} 


\section{Pendahuluan}

Didalam dunia pendidikan modern seperti sekarang ini, seorang guru dituntut untuk dapat meningkatkan kemampuan dan mempunyai wawasan yang luas serta mempunyai konsep yang global dalam menghadapi berbagai tantangan didalam mendidik siswa. Karna khususnya pendidikan teknologi yang baik bagi siswa merupakan pondasi dasar untuk menghadapi tuntutan perkembangan era globalisasi. Sebagian besar sekolah - sekolah di kota besar di Indonesia telah memiliki fasilitas komputer dan atau laboratorium yang telah terhubung dengan jaringan. Adanya jaringan ini diperuntukan untuk mempermudah proses komunikasi dan pertukaran data, maka setiap komputer harus terhubung ke dalam sebuah jaringan komputer.

Jaringan Komputer adalah sekelompok komputer otonom yang saling berhubungan antara satu dengan lainnya menggunakan protokol komunikasi melalui media komunikasi sehingga dapat saling berbagi informasi, program-program, penggunaan bersama perangkat keras seperti printer, harddisk, dan sebagainya (Anjik, 2008). Suatu jaringan komputer terdiri dari komputer, software, dan perangkat jaringan yang bekerja bersama dalam satu ruang lingkup yang disebut jaringan. Jaringan komputer telah menjadi suatu hal penting dalam dunia pendidikan. Banyak sekolah yang menggunakan jaringan komputer untuk membantu kegiatan belajar mengajar. Infrastruktur jaringan komputer merupakan hal yang cukup penting sehingga perlu diperhatikan dan dikelola dengan baik agar kinerja jaringan dapat tetap maksimal.

Sekolah Menengah Kejuruan (SMK) Al-Madani Pontianak belum memiliki sistem jaringan komputer. Sedangkan jaringan komputer sangat diperlukan bagi guru dalam pertukaran informasi serta dalam proses belajar mengajar. Saat ini pengolahan dan penyimpanan data di SMK Al-Madani dilakukan di komputer yang tidak terhubung dengan jaringan. Sehingga guru dan staff tata usaha masih menggunakan sistem manual dalam pertukaran informasi. Oleh karna itu, akan dibangun sebuah system jaringan komputer di sekolah tersebut guna mempermudah pengolahan dan pertukaran informasi.

Dalam membangun sebuah sistem jaringan, terdapat tahapan - tahapan yang harus dilalui sampai dengan jaringan tersebut dapat digunakan. tahap pertama adalah tahapan analisis. Analisis adalah penguraian dari bagian yang utuh kedalam bagian - bagian komponennya dengan maksud untuk mengidentifikasikan dan mengevaluasi permasalahan, kesempatan, hambatan dan kebutuhan yang diharapkan (Jogiyanto, 2005). Setelah dilakukan tahapan analisis ini, diharapkan dapat menemukan permasalahan dan juga solusi yang dapat dilakukan dalam membangun sebuah system jaringan komputer yang terditribusi.

Tujuan dibangunya suatu jaringan komputer adalah membawa informasi secara tepat dan tanpa adanya kesalahan dari sisi pengirim (transmitter) menuju kesisi penerima (receiver) melalui media komunikasi (Anjik: 2008). Ada beberapa hal yang masih dirasa menjadi kendala, yaitu : a). Masih mahalnya fasilitas komunikasi yang tersedia dan bagaimana memanfaatkan jaringan komunikasi yang ada secara efektif dan efisien; b). Jalur transmisi yang digunakan tidak benar - benar bebas dari masalah gangguan (noise). Selain itu, Manfaat yang didapat dalam membangun jaringan Komputer (Winarno, 2010:4), yaitu: a). Sharing resources; b) Media komunikas; c) Integrasi Data; c) Pengembangan dan Pemeliharaan; d) Keamanan Data; dan e) Sumber daya Lebih Efisien dan Informasi terkini. Selanjutnya, jenis - jenis sistem jaringan komputer yang dapat dibangun berdasarkan jarak dan area kerjanya jaringan komputer dibedakan menjadi tiga kelompok (Stalling, 2007), yakni: a) Local Area Network (LAN); b) Metropolitan Area Network (MAN); dan c) Wide Area Network (WAN).

Berdasarkan hasil analisis yang akan dilakukan, akan ditemukan permasalahan dalam membangun sebuah system jaringan komputer yang ada di SMK Al -Madani Kota Pontianak. Berdasarkan masalah tersebut, maka akan ditemukan solusi terbaik yang nantinya akan dijadikan dasar dalam pembuatan tahap selanjutnya setelah analisis.

\section{Metode}

Penelitian ini merupakan jenis penelitian kualitatif deskriptif. Penelitian kualitatif deskriptif ini digunakan untuk menganalisis sistem jaringan komputer yang dibutuhkan oleh Sekolah Menengah Kejuruan Al-Madani Pontianak. Dengan jenis data primer dan data sekunder. Data primer dalam penelitian ini diperoleh dari seseorang yang berpengaruh dalam proses perolehan data. Sedangkan data sekunder dalam penelitian ini diperoleh berdasarkan observasi langsung kepada pihak terkait.

Teknik analisis data dalam penelitian ini menggunakan analisis deskriptif. Data yang diperoleh melalui observasi dan wawancara. Pengumpulan dan penyusunan data ini dilakukan dengan menggunakan teknik triangulasi. Penelitiani ini dilakukan di Sekolah Menengah Kejuruan Al-Madani Pontianak. 


\section{Hasil dan pembahasan}

Tahap pengumpulan data yang dilakukan dalam penelitian ini dengan menggunakan instrumen wawancara dan instrumen observasi. Subjek wawancara dalam penelitian ini adalah guru dan staff tata usaha. Hasil wawancara di SMK Al-Madani Pontianak menyatakan bahwa jaringan komputer penting untuk di implementasikan di sekolah, karena jaringan komputer dapat mengintegerasikan seluruh komputer yang terdapat di sekolah. Subyek wawancara juga menyatakan bahwa dengan adanya jaringan komputer dapat mempermudah pekerjaan yang dilakukan karena data sudah teintegerasi dengan baik. Dengan adanya jaringan komputer, pengecekkan secara realtime data dapat dilakukan mudah oleh kepala sekolah tanpa harus bertemu langsung dengan para guru dan staff.

SMK Al-Madani Pontianak sudah memiliki laboratorium komputer dengan beberapa fasilitas yang memadai seperti unit komputer, meja, kursi, kipas angin, dan kondisi lantai yang dilapisi oleh karpet. Namun laboratorium tersebut belum terintegrasi dengan jaringan komputer. Berdasarkan hasil subjek wawancara, bahwa laboratorium tersebut sudah mendukung untuk diimplementasikan jaringan komputer. Namun fasilitas-fasilitas pendukung jaringan komputer di laboratorium tersebut belum sepenuhnya tersedia.

Hasil wawancara menyatakan bahwa seluruh ruangan kelas yang tersedia di SMK Al-Madani Pontianak perlu dihubungkan oleh jaringan komputer, dengan tujuan untuk mempermudah dalam penyebaran data dan informasi serta mempermudah kepala sekolah untuk mengontrol aktifitas guru dan staff. Jaringan komputer yang dibutuhkan oleh SMK Al-Madani Pontianak adalah jaringan komputer kabel dan nirkabel. Jaringan komputer kabel digunakan di laboratorium komputer, ruang kepala sekolah, dan ruang tata usaha. Sedangkan jaringan komputer nirkabel digunakan diruang guru untuk membatu para guru yang menggunakan laptop.

Observasi yang dilakukan di SMK Al-Madani Pontianak, yaitu dengan melihat secara langsung kondisi laboratorium komputer. Kesimpulan dari observasi tersebut bahwa fasilitas laboratorium yang tersedia berupa komputer sejumlah 30 unit dengan sistem operasi windows 732 bit. Komputer tersebut digunakan oleh para siswa dalam poses pembelajaran praktikum. Fasilitas lain yang tersedia berupa meja dan kursi komputer untuk para siswa. Intensitas pencahayan di laboratorium komputer dapat dikategorikan baik karena terdapat 4 buah jendela yang berada disisi kanan dan kiri ruangan serta 4 buah lampu yang berada diatas ruangan.

Berdasarkan hasil Analisis data dapat disimpulkan bahwa SMK Al-Madani Pontianak memerlukan sebuah jaringan komputer yang terintegrasi. Baik di dalam laboratorium komputer maupun ruangan kepala sekolah, ruangan guru, dan ruangan tata usaha. Dalam pembuatan jaringan untuk laboratorium komputer, diperlukan 30 unit komputer yang diperlukan untuk digunakan oleh siswa dan 1 unit komputer yang akan digunakan oleh guru. Selain komputer, komponen lainyang dibutuhkan dalam membangun sebuah jaringan di SMK Al-Madani yaitu: : server, kabel jaringan, 2unit switch/hub, 1 unit router, dan 1unit wireless. Selain itu, komponen pelengkap lain yang dibutuhkan dalam laboratorium komputer yang dapat digunakan untuk memaksimalkan pembelajaran di dalam laboratorium adalah 2 unit LCD Proyektor, 2 Unit layar LCD Proyektor, 4 buah lampu untuk pencahayaan, dan juga 2 unit pendingin ruangan.

Komputer yang terdiri dari 30 unit komputer dihubungkan oleh kabel jaringan yang dikendalikan secara penuh oleh server. 30 unit komputer ini diatur oleh komponen switch/hub agar setiap komputer memiliki IP Address yang unik. Switch/hub yang digunakan di laboratorium komputer ini berjumlah 2 unit dimana masing-masing unit memiliki 24 port. Switch/hub 1 menghubungkan 15 komputer dan switch/hub 2 menghubungkan 15 komputer. Untuk menghubungkan kedua switch/hub ini diperlukan komponen router yang terhubung dengan server agar seluruh komputer yang berjumlah 30unit dapat terintegrasi dan saling bertukar informasi.

Sedangkan untuk pembuatan jaringan komputer yang menghubungkan ruangan kepala sekolah, ruangan guru, dan ruangan tata usaha menggunakan komponen wireless. Komponen wireless digunakan kepala sekolah, guru, dan staff untuk mengakses jaringan komputer melalui laptop pribadi. IP Address pada ruangan kepala sekolah, ruangan guru, dan ruangan tata usaha menggunakan IP dynamic.

\section{Simpulan dan saran}

Berdasarkan hasil penelitian, maka dapat ditarik kesimpulan bahwa Sekolah Menengah Kejuruan (SMK) Al-Madani Pontianak merupakan sekolah kejuruan dalam bidang jaringan. Sekolah tersebut telah memiliki fasilitas laboratorium yang memadai, namun belum memiliki fasilitas jaringan komputer yang memadai untuk pertukaran informasi serta pengolahan dan penyimpanan data yang terdistribusi. Hasil 
analisa mengungkapkan bahwa sekolah tersebut belum memiliki fasilitas jaringan komputer seperti: server, router, swith/hub, kabel jaringan, dan wireless.

Berdasarkan hasil penelitian, maka dapat diberikan saran bahwa analisis jaringan komputer ini berfungsi untuk memaksimalkan fungsi dari semua komputer yang ada di Sekolah Menengah Kejuruan (SMK) Al-Madani Pontianak. Baik itu untuk menghubungkan jaringan laboratorium komputer dan juga semua komputer yang ada di SMK tersebut. Supaya dalam penggunaanya, penyebaran dan pengelolaan data dapat dikelola dengan maksimal.

\section{Daftar Rujukan}

Anjik Sukmaaji \& Rianto. 2008. “Jaringan Komputer Konsep Dasar Pengembangan Jaringan \& Keamanan Jaringan".Yogyakarta: Andi.

Arikunto, S., 2006. Prosedur Penelitian Suatu Pendekatan Praktik. Jakarta: Rineka Cipta.

Alexander Pandu Baskoro. 2011. “Analisis dan Perancangan Jaringan Komputer Studi Kasus: Inna Garuda Yogyakarta”. Tugas AkhirProram Studi Teknik Informatika Universitas Atma Jaya Yogyakarta.

Basrowi \& Suwandi. 2008. Prosedur Penelitian Tindakan Kelas. Bogor: Ghalia Indonesia.

Jogiyanto. 2005. Analisis \& Desain Sistem Informasi: Pendekatan Tersruktur Teori dan Praktik Aplikasi Bisnis. Yogyakarta: Andi Offset.

Singarimbun, Masir, dan Efendi S. 1989. Metode Penelitian Survei. Jakarta: LP3S.

Stalling, William. 2007. “Komunikasi \& Jaringan Nirkabel”. Jakarta: Erlangga.

Soeratno, 1995. Metodologi Penelitian. Yogyakarta: UUP AMP YKPN.

Meylan Anggara, Yesi Novaria Kunang. (2013). "Analisis dan Arsitektur Desain Jaringan Komputer SMA Negeri 1 Muara Enim". Tugas Akhir Jurusan Teknik Informatika Universitas Bina Darma, Palembang.

Muhammad Nur Ikhsanto, Handoyo Widi Nugroho. (2015). "Analisa Performa dan Desain Jaringan Kompute Menggunakan Top - Down Network Desain Studi Kasus pada CV. Merah Putih". Jurnal TIM Darmajaya Vol.01 no 01. Mei 2015. ISSN: 2442 - 5567.

Riyanto, Umi Fadlilah, Muhammad Kusban. (2013). "Analisis dan Perancangan Kemanan Jaringan Kabel dan Nirkabel pada Kantor Imigrasi Kelas II Kabupaten Karawang". Tugas Akhir Program Studi Teknik Informatika Universitas Muhammadiyah Surakarta: Surakarta.

Tanenbaum, Andrew.S. (1997). “Jaringan Komputer”. Jilid 1. Prenhallindo. Jakarta

Tittel, Ed. 2002. “Schaum’s Outlines Computer Networking”. Jakarta: Erlangga.

Williams, Brian.K. (2003). "Using Information Technology: A Practical Introduction to Computers and Communications". McGrawHilll.NY

Winarno Sugeng. 2010. "Jaringan Komputer dengan TCP/IP". Bandung: Modula.

Winarno Sugeng, Indah Septiem Mery. (2012). "Analisis Jaringan Komputer Dinas Komunikasi dan Informatika". Jurnal Informatika No. 1, Vol 3, Januari - April 2012. 